$\xi=-1$

\title{
Design of CPW fed f-shaped circularly polarized antenna for amateur radio vehicular communications
}

\author{
T. V. Ramakrishna ${ }^{1}$, B.T.P. Madhav ${ }^{1}$, D. Amulya ${ }^{1}$, S. Sumitra ${ }^{1}$, A. Sai Kumar ${ }^{1}$, M. Rohit ${ }^{1}$, T. Anilkumar ${ }^{1}$ \\ ${ }^{1}$ Department of Electronics \& Communication Engineering, Koneru Lakshmaiah Education Foundation, Guntur, India \\ *Corresponding author E-mail: btpmadhav@kluniversity.in
}

\begin{abstract}
In this paper a compact circularly polarized antenna is proposed to operate in X-band spectrum. The F-shaped monopole element is used as the radiating structure and the closed coplanar-waveguide ground is used on a FR4 substrate. The proposed feeding mechanism with asymmetric ground planes and the three rectangular strips connected to the feed line. The proposed antenna operates with a $-10 \mathrm{~dB}$ reflection coefficient bandwidth from $9.3 \mathrm{GHz}$ to $13 \mathrm{GHz}$ and the circular polarized performance is attained from $9.8 \mathrm{GHz}-11.2 \mathrm{GHz}$ with axial ratio less than $3 \mathrm{~dB}(\mathrm{AR}<3 \mathrm{~dB})$. The antenna gain in the boresight direction is found to be achieved as $4.34 \mathrm{~dB}$ and radiates with a maximum efficiency of $90 \%$ which is suited for amateur radio applications in X-band spectrum based vehicular communications.
\end{abstract}

Keywords: Amateur Radio; Asymmetric Ground; Axial Ratio (AR); Circular Polarization; Closed CPW Ground; F-Shaped Monopole.

\section{Introduction}

Nowadays the importance of the wireless communications has been emerging under the circumstances of crisis and natural calamities. An emergency communication system is required when a wired line, cellular phones and other traditional communication systems break down. In such a case a dedicated microwave spectrum for recreation and for exchanging the non-commercial messages, emergency communication, self-training purposes. The International Telecommunication Union (ITU) provided the radio regulations for $10-10.5 \mathrm{GHz}$ band allowing the Amateur Radio operations [1]. This is also known as Ham radio and will be helpful for the people to contact with space, town, across the world without any mobiles and information from network. The communication systems with low-profile in dimensional aspect and high in reliability are preferred mostly. The antenna being the most important entity in such a system to work as a key trans-receiving element should possess excellent radiation performance along with its impedance matched bandwidth, polarization capability, radiation efficiency, gain etc.

Printed monopole antennas are most suitable for handheld devices owing to their features of light weight, low cost [2]. Antennas with circular polarized radiation capability mostly preferred because of the reason that the signals propagate through the atmosphere usually become de-polarized which causes undesirable reception of the opposing polarity of the signal and may cause poor quality in reception. To improve reliability of the system the signal can be captured from any direction regardless of the antenna orientation as in case of linear polarization. There are many techniques to achieve $\mathrm{CP}$ radiation presented in literature and some of which are outlined here. A square patch antenna with cross-slot coupling which is excited by a microstrip line is used in [3] to obtain circularly polarized performance in $2.4 \mathrm{GHz}$ ISM band. A technique to achieve the CP radiation is mentioned in [4] by using a coplanar capacitive feed and a slot in the rectangular patch which is designed on a suspended substrate. In [5], proposed a new circularly polarized Metasurface Dipole Antenna (MSDA) with wide axialratio beamwidth and radar cross section (RCS) reduction properties. An antenna with conical-disc backed Archimedian single-arm spiral is proposed in [6] for X-band applications is exhibiting circular polarization. In [7], the CP radiation performance is achieved through incorporating the branched microstrip feedline which excites the triangular monopole on a compact substrate. To operate the antenna in circular polarization, in [8], a hexagonal shaped patch is used and the diagonal slots are made within the patch and proposed for ITS applications. A broadband CPW fed antenna is proposed with circular polarized radiation is proposed in [9]. It is achieved by placing an open-end slot at the lower side of the antenna structure. A monopole radiator with two orthogonal sections and the parasitic elements provides the quadrature phase difference to create circular polarized radiation performance which was proposed in [10]. In [11], a compact structured planar cross-shaped monopole antenna is proposed with enhanced impedance bandwidth by employing a slot in the ground plane and this broadband nature is attained in $\mathrm{CP}$ radiation by extending the one side of the ground plane. A $45^{0}$-rotated square slot in ground plane excited by a microstrip line radiator in [12] caters the $\mathrm{CP}$ radiation with the incorporation of a pair of stubs on opposite sides of that slot. Researchers proposed different models with $\mathrm{CP}$ with compact dimensions and good axial ratio bandwidth [13-22]. In this work, a planar and compact antenna design is proposed. The geometrical attributes with iterative designs and related specifications are discussed in section II. Further, the design optimization is presented in Section III with parametric study on critical performance effecting parameters. The simulation results and its analysis are outlined in Section IV with clear description of radiation functionality of the proposed antenna.

\section{Antenna design}

The design process of the compact coplanar waveguide fed antenna initializes with the modelling a CPW structure with two ground 
planes on either side with width of the ground being ' $\mathrm{W}_{\mathrm{g} 1}$ '. The length of the feed line is considered as ' $\mathrm{L}_{\mathrm{f}}$ '. The feed line is extended with an additional length of ' $\mathrm{L}_{1}$ ' to make it operating as a radiating stub. The entire structure is designed on a FR4 substrate which is having relative permittivity of 4.4 and loss tangent of 0.02. The substrate is having dimensions of $L_{s} \times W_{s} \times h$. This structure with only CPW structure and extended feed line forms the first iteration. In the next version of its geometry, two ground planes are connected with a small strip of width ' $t 1$ '. This design forms the second iteration and forms the closed ground structure. In the third iteration, some geometrical modification $\mathrm{s}$ are applied to the radiating stub and coplanar ground conductors are modified in such a way that the asymmetrical ground lengths are applied with length ' $\mathrm{L}_{\mathrm{g}}$ ' for the left side ground and length ' $\mathrm{L}_{\mathrm{g} 2}$ ' for right side ground. A horizontal rectangular strip with length ' $b_{1}$ ' and width ' $t_{1}$ ' respectively is connected to the extended feedline. This horizontal strip is placed at a height ' $\mathrm{a}_{1}$ ' from the left side ground. The model in iteration- 4 continues with the same geometry with an additional balanced stub with dimensions $b_{3} \times t_{3}$ appended to the left edge of the vertical radiating strip at a distance ' $a_{2}$ ' from the right sided ground plane. The final version of the antenna constitutes another horizontal stub with dimensions $\mathrm{b}_{2} \mathrm{xt}_{2}$. This structure forms the F-shaped radiating element. The ground planes with asymmetrical lengths and the three rectangular strips are the major elements in this antenna design for making the antenna to operate in X-band and with circular polarization performance. The geometrical parameters of the antenna are tabulated in Table 1.
(A)

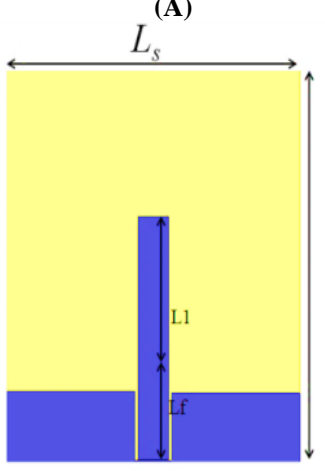

(C)

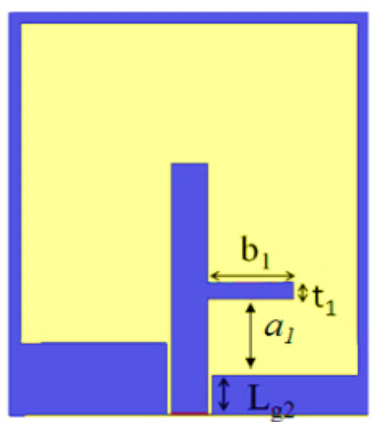

(B)

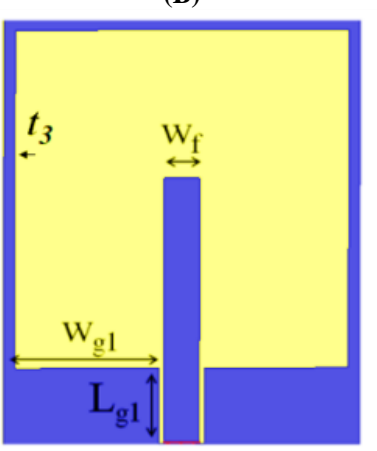

(D)

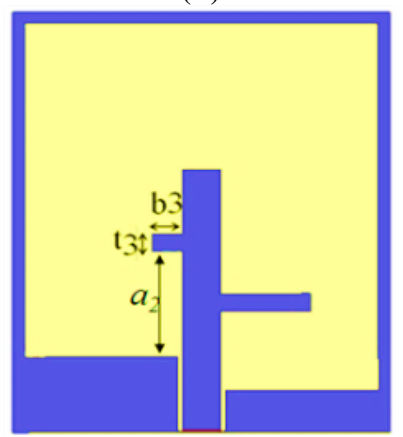

(E)

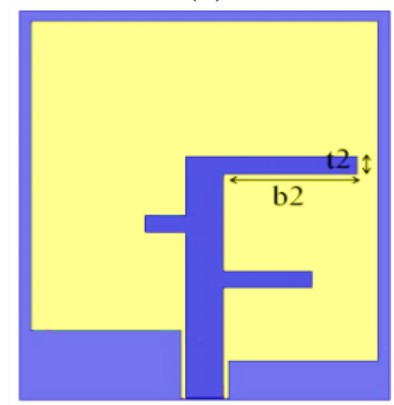

Fig. 1: Antenna Structure (A) Antenna-1 (B) Antenna-2 (C) Antenna-3 (D) Antenna-4 (E) Proposed Antenna.
Table 1: Geometrical Parameters of the Proposed Antenna

\begin{tabular}{llllllllll}
\hline $\begin{array}{l}\text { Parame- } \\
\text { ter }\end{array}$ & $\mathrm{L}_{\mathrm{s}}$ & $\mathrm{W}_{\mathrm{s}}$ & $\mathrm{h}$ & $\mathrm{L}_{\mathrm{f}}$ & $\mathrm{W}_{\mathrm{f}}$ & $\mathrm{W}_{\mathrm{g}}$ & $\mathrm{L}_{1}$ & $\mathrm{~L}_{\mathrm{g} 1}$ & $\mathrm{~L}_{\mathrm{g} 2}$ \\
\hline $\begin{array}{l}\text { Value in } \\
\text { mm }\end{array}$ & 57. & 31. & 1. & 10 & 3.2 & 13.7 & 13. & 6.7 & 3.7 \\
$\begin{array}{l}\text { Parame- } \\
\text { ter }\end{array}$ & $\mathrm{t}_{1}$ & $\mathrm{t}_{2}$ & $\mathrm{t}_{5}$ & $\mathrm{a}_{1}$ & $\mathrm{a}_{2}$ & $\mathrm{a}_{3}$ & $\mathrm{~b}_{1}$ & $\mathrm{~b}_{2}$ & $\mathrm{~b}_{3}$ \\
$\begin{array}{l}\text { Value in } \\
\text { mm }\end{array}$ & 1 & 1 & 1. & 7.0 & 9.3 & 9.4 & 7.5 & 11. & 2.5 \\
& & & 6 & 5 & 5 & & & 4 & \\
\hline
\end{tabular}

\section{Parametric study}

The proposed antenna is modelled with the help of several parameters and processed through several iterations. The modelling of the antenna is carried out in High Frequency Structure Simulator tool in ANSYS Electronics Desktop v.17.2 package. The behaviour of the antenna while changing the values of those important parameters is studied and presented in this section.

\subsection{Effect of variation in length of the lower rectangular strip 'b1'}

Fig. 2 shows the parametric analysis of length ' $b_{1}$ '. Here ' $b_{1}$ ' represents the length of the strip on the right side which is near to the ground. This length is varied from the value $5.2 \mathrm{~mm}$ to $8 \mathrm{~mm}$.

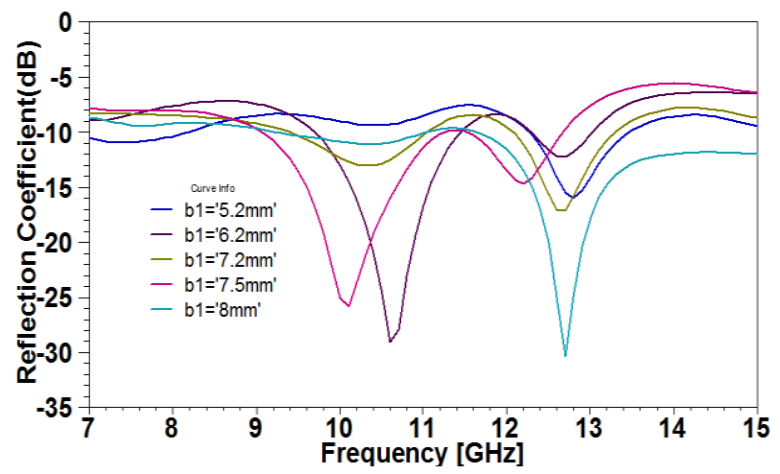

Fig. 2: Parametric Study of ' $B_{1}$ ' on $S_{11}$ Characteristics of the Antenna.

It is found that the increase in the length reduces the reflections in the desired band. Thus, an optimum solution is obtained at $7.5 \mathrm{~mm}$. When this parameter exceeds the $7.5 \mathrm{~mm}$ the lower band below the center frequency $11 \mathrm{GHz}$ is going to be reduced and the resonances are shifted to higher frequencies near $13 \mathrm{GHz}$.

\subsection{Effect of variation in length of the upper rectangu- lar strip 'b2'}

The parametric study on length of the upper rectangular strip which is appended on the top of the vertical rectangular strip is varied from $6.8 \mathrm{~mm}$ to $11.4 \mathrm{~mm}$ with step variation of $1.6 \mathrm{~mm}$ which is shown in Fig. 3. The lower the length of the upper horizontal strip is creating the resonant behavior of the antenna in between the $12 \mathrm{GHz}-13 \mathrm{GHz}$ band. Further increasing its length significantly introduces the resonance behavior near $9-11 \mathrm{GHz}$ region thus creating a wideband performance at $11.4 \mathrm{~mm}$ length. 


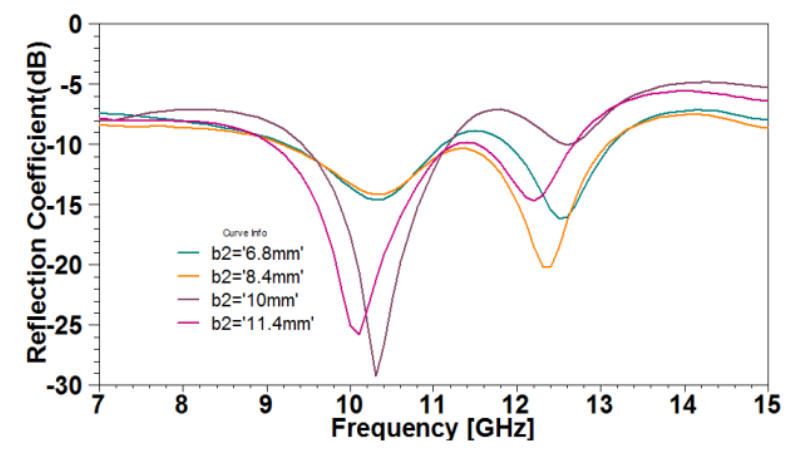

Fig. 3: Parametric Study of ' $\mathrm{B}_{2}$ ' On $\mathrm{S}_{11}$ Characteristics of the Antenna.

\subsection{Effect of variation in length of the ground plane 'Lg1' and 'Lg2'}

The ground plane plays an important role for an antenna design and hence in this section the lengths of the either ground plane parameters are varied. The length of the left-sided ground plane is varied from $4.5 \mathrm{~mm}$ to $6.75 \mathrm{~mm}$ with step incremental variation of $1.25 \mathrm{~mm}$ which is shown in Fig. 4(a). It can be observed from the Fig. 4(a) that the lower the ground length makes the antenna to operate under $12 \mathrm{GHz}-15 \mathrm{GHz}$ band and this behavior continues till the value reaches to $6 \mathrm{~mm}$. After another $1.25 \mathrm{~mm}$ stepincremental variation the resonance which is already existing at 13.6 GHz, $13.2 \mathrm{GHz}, 13 \mathrm{GHz}$ is shifted to $12.2 \mathrm{GHz}$ and an additional resonance at $10.2 \mathrm{GHz}$ is attained which shows the better impedance matching and enhanced bandwidth which falls under 9 $\mathrm{GHz}$ to $12.5 \mathrm{GHz}$ spectrum.

(A)

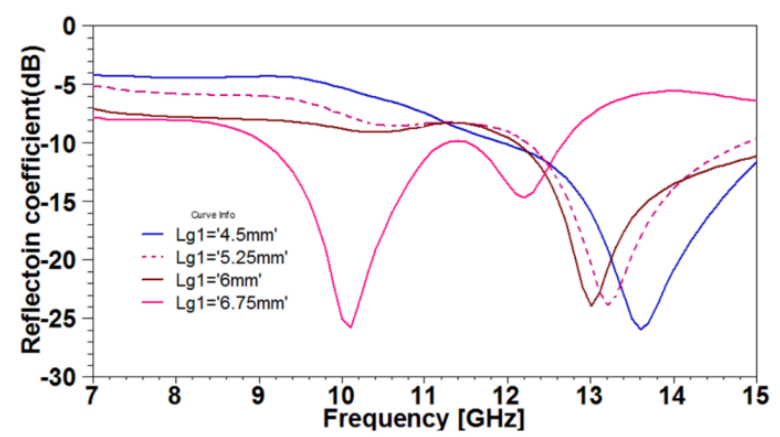

(B)

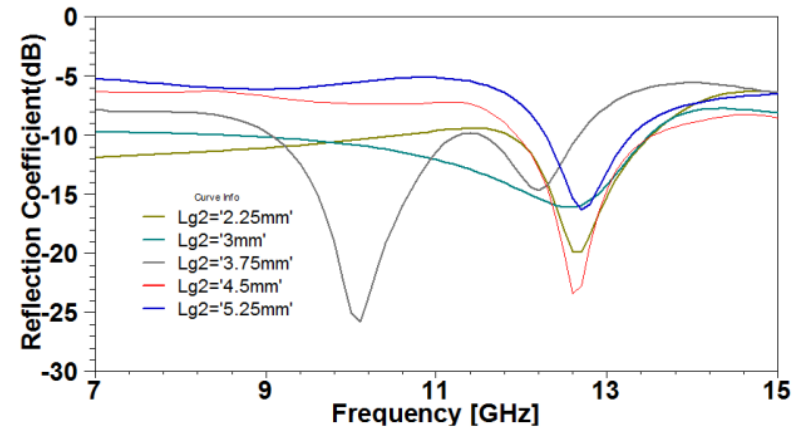

Fig. 4: Parametric Study of (A) Length ' $\mathrm{L}_{\mathrm{g} 2}$ ' (B) Length ' $\mathrm{L}_{\mathrm{g} 1}$ ' on the $\mathrm{S}_{11}$ Characteristics of the Antenna.

Similar behavior is observed when the length of the right-sided ground plane is varied from $2.25 \mathrm{~mm}$ to $5.25 \mathrm{~mm}$. It is observed that for the variation in the ' $\mathrm{Lg} 2$ ' parameter from $2.25 \mathrm{~mm}$ to $3.75 \mathrm{~mm}$, the antenna resonates at $12.6 \mathrm{GHz}$ and maintains consistency at its operating resonance. Moreover, the reflection losses are minimized and attained at level nearer to $-22 \mathrm{~dB}$ reflection coefficient. At $5.25 \mathrm{~mm}$ length, this resonance shifts towards 12.3 $\mathrm{GHz}$ and the additional lower resonance at $10.2 \mathrm{GHz}$ is attained with a reflection coefficient of $-27 \mathrm{~dB}$. This can be due to the de- creasing the distance between the left-sided ground and lower rectangular stub which is connected to the feed line on the right side.

\section{Simulation results and discussion}

After modelling and parametric study on the different geometrical parameters, the influence of such variations is observed and the optimal parameters are finalized. Finally, the parametrically optimized antenna is simulated for knowing the other quality parameters of the antenna which are discussed in this section.

\subsection{Reflection coefficient characteristics}

The reflection coefficient is the important parameter for the antenna design which gives the information regarding the effectiveness of impedance matching to a certain frequency fed to the input port of the antenna. The reflection coefficient characteristics of the antenna obtained through antenna simulation in HFSS are presented in Fig. 5. For computing the antenna operating bandwidth, the $10 \mathrm{~dB}$ line is considered as reference. The characteristics which fall under $-10 \mathrm{~dB}$ will be considered as operating band of the antenna.

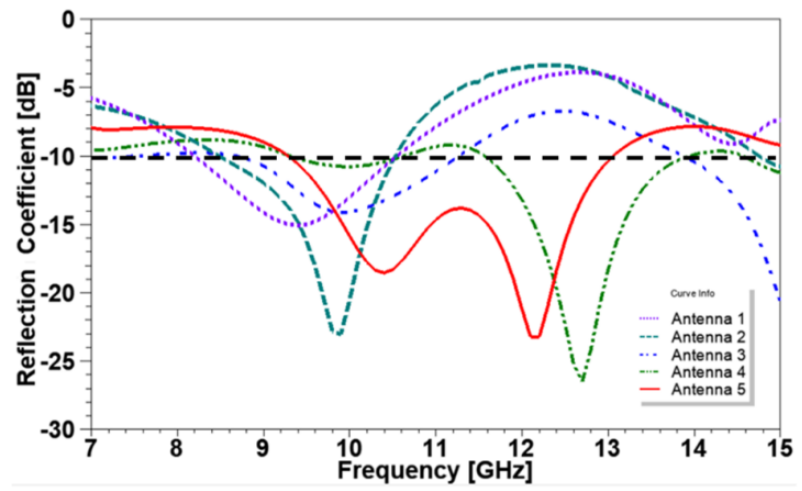

Fig. 5: Simulated Reflection Coefficient Characteristics of Different Geometrical Iterations of the Proposed Antenna.

The antenna structure with the CPW feed and having the extended feed line operates from 8.1-10.4 GHz band, whereas the closed ground structure which is incorporated in the second iteration creates the deeper resonance at $9.8 \mathrm{GHz}$ and operates from 8.5 $10.45 \mathrm{GHz}$. The third iteration in which the ground planes with the asymmetrical lengths and appended the lower rectangular strip. By adding the structure, the antenna tends to operate from $8.9 \mathrm{GHz}$ $11.3 \mathrm{GHz}$ and an additional operating band is observed from 13.8 $\mathrm{GHz}$, extends beyond $15 \mathrm{GHz}$. In this case, the primary operating band which has been existing since earlier iterations is decaying and the second band is shifted from $15 \mathrm{GHz}$ to $12.75 \mathrm{GHz}$. The antenna iteration- 4 thus operates from $11.7 \mathrm{GHz}$ to $13.8 \mathrm{GHz}$. In the fifth iteration of the antenna design the extension of vertical feedline with a larger rectangular strip on its top is provided. This decreased the obtained resonance frequency towards $12.2 \mathrm{GHz}$ and the primary, secondary operating bands are merged together thus creating wider band width from $9.3-13 \mathrm{GHz}$. The proposed antenna iteration covers maximum of X-band spectrum.

\subsection{Circular polarization performance of the proposed antenna}

Axial ratio parameter is used to assess the antenna whether it is radiating with circularly polarized performance or not. The theoretical value of axial ratio (AR) is $0 \mathrm{~dB}$, however, the $3 \mathrm{~dB}$ value is considered for computation of axial ratio bandwidth of the antenna In this case, the proposed antenna radiates with circular polarization from $9.8 \mathrm{GHz}-11.2 \mathrm{GHz}$ which covers the amateur radio applications in X-band as shown in Fig. 6. 


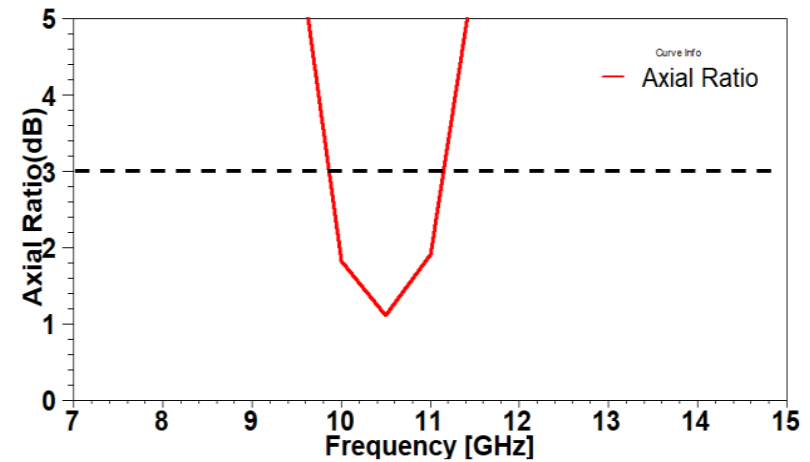

Fig. 6: Simulated Axial Ratio vs. Frequency Characteristics of the Proposed Antenna.

The surface current element distribution patterns also will give the clear idea of the circular polarization in the desired band. These patterns are presented in Fig. 7 simulated at different phase angles. These patterns are simulated at $10.5 \mathrm{GHz}$ at which the minimum axial ratio of $1.15 \mathrm{~dB}$ is achieved. The patterns at different quadrature phase shifts indicate the orientation and movement of the current elements in a circular motion. The quiet opposite orientation of current elements can be observed for $0^{\circ}$-phase and $180^{\circ}$ phase, $90^{\circ}$-phase and at $270^{\circ}$-phase respectively. The ground planes with asymmetric lengths and the connected rectangular strips makes the antenna to radiate with circular polarization.
(A)

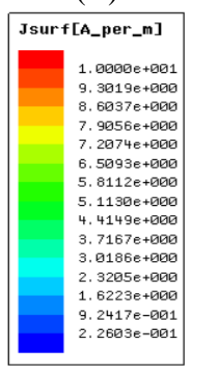

(C)

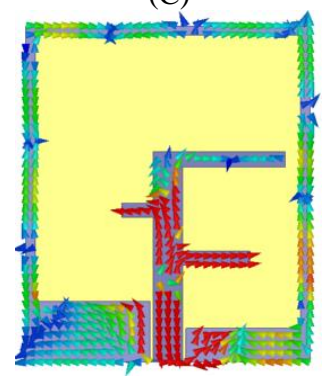

(B)

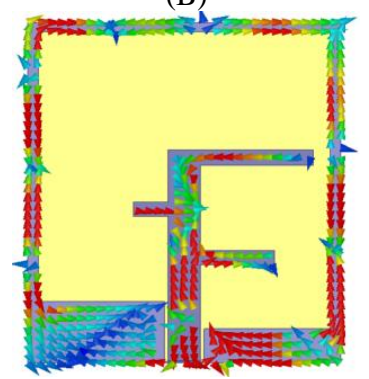

(D)

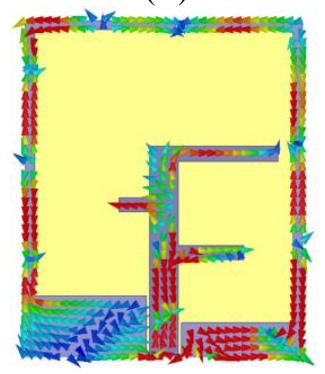

(E)

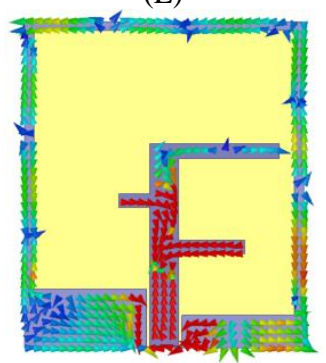

Fig. 7: Surface Current Distribution Patterns of the Proposed Antenna Obtained at $10.5 \mathrm{Ghz}$ Frequency (A) at $0^{0}$-Phase (B) at $90^{\circ}$-Phase (C) at $180^{\circ}$-Phase (D) at $270^{\circ}$-Phase.

\subsection{Radiation Performance of the proposed antenna}

The radiation patterns of the proposed antenna are presented in Fig 8. After the determination of circular polarization characteristics of the proposed antenna, the radiation patterns which are plotted below decides the left-handed or right-handed polarization behavior of the antenna.
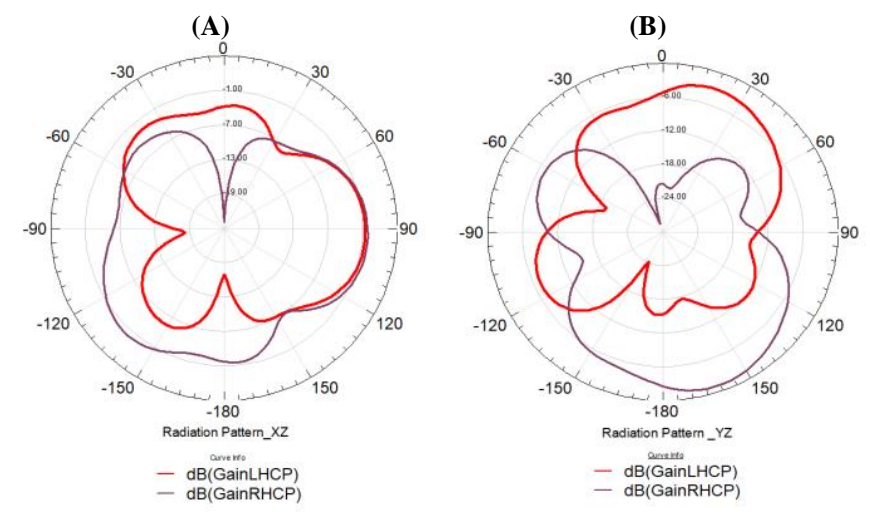

(C)

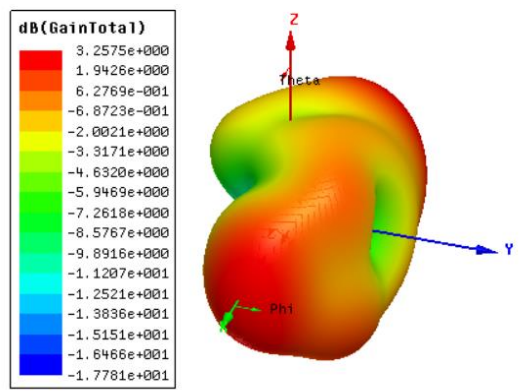

Fig. 8: Far-Field Radiation Patterns of the Proposed Antenna Obtained at 10.5 Ghz Frequency (A) E-Plane (B) H-Plane (C) 3D Far-Field Characteristics.

From the Fig. 8 (a) and 8 (b), in both E- and H-planes the RHCP patterns are slightly dominant one and thus the proposed antenna possess the RHCP radiation. The 3D far-field characteristics are shown in Fig. 8 (c). The overall antenna performance characteristics are presented in Table 2. 


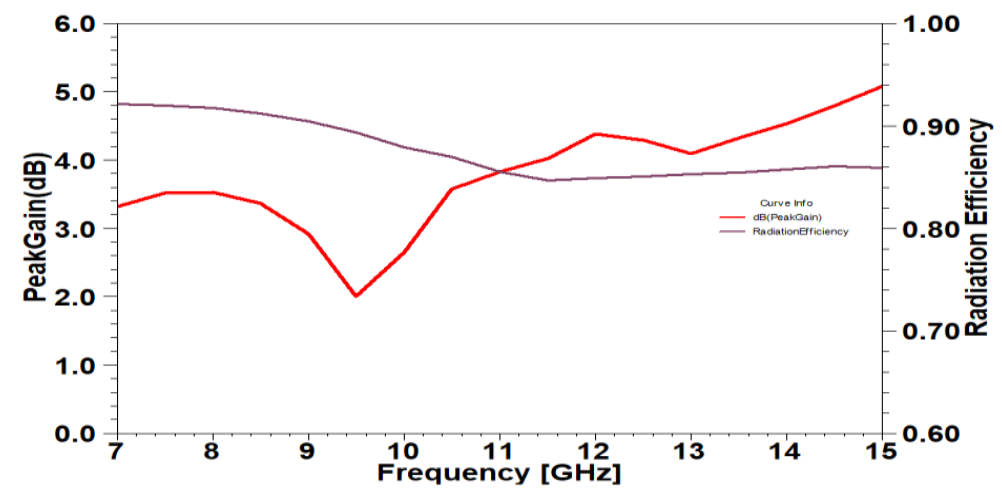

Fig. 9: Simulated Peak Gain and Radiation Efficiency vs. Frequency Characteristics of the Proposed Antenna.

Table 2: Geometrical Parameters of the Proposed Antenna

\begin{tabular}{|c|c|c|c|c|c|c|}
\hline Antenna Iterations & Operating bands $(\mathrm{GHz})$ & $\begin{array}{l}\text { Resonant } \\
\text { Frequencies }\end{array}$ & $\mathrm{S}_{11}(\mathrm{~dB})$ & $\begin{array}{l}\text { Axial Ratio Band- } \\
\text { width }\end{array}$ & $\begin{array}{l}\text { Peak Gain } \\
(\mathrm{dB})\end{array}$ & $\begin{array}{l}\text { Radiation Efficien- } \\
\text { cy }(\%)\end{array}$ \\
\hline Ant 1 & $8.2-10.5$ & 9.4 & -15.0 & NA & 5.1 & 89.23 \\
\hline Ant 2 & $8.4-10.6$ & 9.9 & -23.0 & NA & 5.5 & 89.15 \\
\hline Ant 4 & $11.5-14$ & 12.7 & -26.5 & $10.7-11.6$ & 3.968 & 84.04 \\
\hline Ant 5 (Proposed) & $9.3-13$ & 10.5 & -9.78 & $9.8-11.1$ & 5.3 & 90.01 \\
\hline
\end{tabular}

\section{Conclusion}

In this paper, a compact $37.5 \times 31.5 \times 1.6 \mathrm{~mm} 3$ planar antenna is presented for handheld devices. The CPW structure is used which provides better compatibility to integrate with MMIC circuits. The proposed design not only shows the $-10 \mathrm{~dB}$ impedance bandwidth across $9.3-13 \mathrm{GHz}$ over which $37.83 \%$ of the bandwidth $(13.3 \%$ AR bandwidth i.e., from $9.8-11.2 \mathrm{GHz}$ ) is having circularly polarized characteristics. Over the entire footprint of the substrate, the radiating elements and ground structures occupies less amount of area and gives good radiation performance of the antenna with a maximum gain of $4.34 \mathrm{~dB}$. The radiation efficiency is excellent noted a value of $90 \%$.

\section{Acknowledgement}

The authors deeply express their gratitude to ALRC Research Centre, Department of ECE, Koneru Lakshmaiah Education Foundation for their encouragement during this work. Further, Madhav would like to express his gratitude to Department of Science and Technology, India through grant ECR / 2016 / 000569, EEQ / 2016 / 000604 and FIST grant SR / FST / ETI-316 / 2012.

\section{References}

[1] VHF Handbook of IARU Region 1 (2006), pg. 50 Archived February 5, 2009, at the Wayback Machine.

[2] Krishna, V.S., et al. (2016), High Bandwidth Circularly Polarized X-Slot Antenna. Far East Journal of Electronics and Communications 16(3), p.561. https://doi.org/10.17654/EC016030561.

[3] W. Haboubi, H. Takhedmit, J.-D. Lan Sun Luk, S.-E. Adami, B. Allard, F. Costa, C. Vollaire, O. Picon, and L. Cirio (2014), an efficient dual-circularly polarized rectenna for RF energy harvesting in the $2.45 \mathrm{GHz}$ ISM band. Progress In Electromagnetics Research 148, 31-39. https://doi.org/10.2528/PIER14031103.

[4] V. G. Kasabegoudar and K. J. Vinoy (2009), A broadband suspended microstrip antenna for circular polarization. Progress In Electromagnetics $\quad$ Research $\quad 90,353-368$. https://doi.org/10.2528/PIER09012901.

[5] C. Chen, Z. Li, L. Liu, J. Xu, P. Ning, B. Xu, X. Chen, and C. Q. $\mathrm{Gu}$ (2015), A broadband suspended microstrip antenna for circular polarization. Progress In Electromagnetics Research 154, 79-85. https://doi.org/10.2528/PIER15092401.

[6] Ur-Rehman, M., Safdar, G. A., Yang, X., \& Chen, X. (2017), Design and study of a circular polarised conical-disc-backed spiral an- tenna for X-Band applications. IEEE Access 5, 21344-21354. https://doi.org/10.1109/ACCESS.2017.2758765.

[7] Y.M.Cai, K. Li, Y.-Z. Yin, and W. Hu. (2014), Broadband Circularly Polarized printed antenna with branched microstrip feed. IEEE Antennas Wireless Propag. Lett. 13, 674-677. https://doi.org/10.1109/LAWP.2014.2314317.

[8] Mondal, T., Samanta, S., Ghatak, R. and Chaudhuri, S. R. B. (2015) A novel hexagonal wideband circularly polarized stacked patch microstrip antenna. IMicrow. Opt. Technol. Lett. 57, 2548-2554. https://doi.org/10.1002/mop.29383.

[9] Madhav, B. T. P., Habibulla Khan, and Sarat K. Kotamraju (2016), Circularly polarized slotted aperture antenna with coplanar waveguide fed for broadband applications. Journal of Engineering Science and Technology 11(2), 267-77.

[10] R. K. Saini, S. Dwari and M. K. Mandal (2017), CPW-Fed DualBand Dual-Sense Circularly Polarized Monopole Antenna. IEEE Antennas and Wireless Propagation Letters 16, 2497-2500. https://doi.org/10.1109/LAWP.2017.2726545.

[11] K. O. Gyasi et al. (2017), A Compact Broadband Cross-Shaped Circularly Polarized Planar Monopole Antenna with a Ground Plane Extension. IEEE Antennas and Wireless Propagation Letters 17(2), 335-338. https://doi.org/10.1109/LAWP.2018.2789430.

[12] Sheik, A. R., et al.,"Circularly Polarized Defected Ground Broadband Antennas for Wireless Communication Applications", Proceedings of 2nd International Conference on Micro-Electronics, Electromagnetics and Telecommunications, (2018), pp: 419-427. https://doi.org/10.1007/978-981-10-4280-5 44.

[13] Asa Jyothi, "A Novel Compact CPW- Fed Polarization Diversity Dual Band Antenna using H-Shaped Slots", Indian Journal of Science and Technology, (2016), 9(37), pp 1-8. https://doi.org/10.17485/ijst/2016/v9i38/93378.

[14] M. Ajay Babu, B. T. P. Madhav, B. Mohan Reddy, R. Divya Chaitanya, T. Satish and T. Anilkumar, A Dual-Polarization Reconfigurable Antenna with Beam Switching Characteristics For S-Band Applications, ARPN Journal of Engineering and Applied Sciences, ISSN 1819-6608, Vol. 12, No. 16, Aug 2017, pp 4841-4847.

[15] K V L Bhavani, Habibulla Khan, "Multiband Slotted Aperture Antenna with Defected Ground Structure For C And X-Band Communication Applications", Journal of Theoretical and Applied Information Technology, (2015), 82(3), pp 454-461.

[16] B.T.P.Madhav, Prof. VGKM Pisipati, K V L Bhavani, P.Sreekanth, P.Rakesh Kumar, "Rectangular Microstrip Patch Antenna on Liquid Crystal Polymer Substrate", Journal of Theoretical and Applied Information Technology, (2010), 18(1).

[17] B T P Madhav, Habibulla Khan, D Ujwala, Y Bhavani Sankar, Madhuri Kandepi, A Siva Nagendra Reddy, Davuluri Nagajyothi, "CPW Fed Serrated Antenna Performance Based on Substrate Permittivity", International Journal of Applied Engineering Research, (2013), 8(12), pp. 1349-1354.

[18] B.T.P. Madhav, V.G.K.M. Pisipati, Habibulla Khan, V.G.N.S. Prasad, K. Praveen Kumar, K.V.L. Bhavani and P.V. Datta Prasad, "Microstrip 2x2 Square Patch Array Antenna on K15 Liquid Crys- 
tal Substrate", International Journal of Applied Engineering Research, (2011), 6(9) pp. 1099-1104

[19] B.T.P.Madhav, VGKM Pisipati1, Habibulla Khan, V.G.N.S Prasad, K. Praveen Kumar, KVL Bhavani and M.Ravi Kumar, "Liquid Crystal Bow-Tie Microstrip antenna for Wireless Communication Applications", Journal of Engineering Science and Technology Review, (2011), 4 (2), pp 131-134.

[20] B.T.P. Madhav, D. Ujwala, Habibulla Khan, Atluri Lakshmi Tejaswani, Sriram Guntupalli and Atluri Bala, "Substrate Permittivity Effects on the Performance of Slotted Aperture Stacked Patch Antenna", International Journal of Applied Engineering Research, (2013), 8(8), pp. 909-916.

[21] B T P Madhav, VGKM Pisipati, Habibulla Khan, D Ujwala, "Fractal shaped Sierpinski on EBG structured ground plane", Leonardo Electronic Journal of Practices and Technologies, (2014), 25, pp 26-35.

[22] B.T.P. Madhav, S.S. Mohan Reddy, J. Ravindranath Chowdary,V. Vinod Babu, S.S. Satya Parthiva, S. Kalyana Saravana, "Analysis of Dual Feed Asymmetric Antenna", International Journal of Applied Engineering Research, (2013), 8(4), pp. 361-367. 